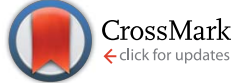

Cite this: J. Anal. At. Spectrom., 2014, 29, 1806

Received 20th December 2013 Accepted 26th June 2014

DOI: 10.1039/c3ja50398d

www.rsc.org/jaas

\section{Fast determination of the surface density of titanium in ultrathin layers using LIBS spectrometry}

\author{
Tomáš Kratochvíl, ${ }^{a}$ Tomáš Černohorský, ${ }^{\star a}$ Petr Knotek, ${ }^{\mathrm{b}}$ Lukáš Kalina, ${ }^{\mathrm{c}}$ \\ Jakub Návesnik, ${ }^{a}$ Miloslav Pouzar ${ }^{a}$ and Magdalena Zvolskáa
}

\begin{abstract}
This work deals with the use of laser-induced breakdown spectroscopy (LIBS) for determining the surface density of titanium in ultrathin layers, particularly in ultrathin layers on a steel sheet. The results obtained by LIBS spectroscopy were compared with those obtained by wavelength dispersive $X$-ray fluorescence spectroscopy (WDXRF), X-ray photoelectron spectroscopy (XPS) and laser ablation inductively coupled plasma time of flight mass spectrometry (LA-ICP-TOF-MS). A simple, cheap and efficient method for the determination of the surface density of titanium in thin layers has been developed.
\end{abstract}

\section{Introduction}

Thin films of titanium are widely used in many fields of materials science. The main reason for the use of Ti coating is the excellent corrosion resistance to many highly corrosive substances. The high corrosion resistance of titanium films results from the formation of very stable, continuous, highly adherent, and protective oxide films on metal surfaces. In the production process, it is necessary to control the thickness of the titanium layer on the substrate. An effective way of monitoring the amount of titanium deposited on the substrate is determination of the surface density of titanium.

In recent years a number of analytical methods have become available for depth profiling of solid surfaces. The most commonly used techniques for the chemical characterization of thin films are expensive and time consuming (see, for example, X-ray photoelectron spectroscopy (XPS), ${ }^{\mathbf{1}, 2}$ X-ray diffraction (XRD), ${ }^{3,4}$ Auger electron spectroscopy (AES), ${ }^{5}$ secondary ions mass spectrometry (SIMS), ${ }^{6}$ ) or limited in terms of the sample geometry towards the excitation source (Glow discharge optical emission spectrometry (GDOES) $\left.)^{7}\right)$. Furthermore, the operation of the above mentioned techniques is usually expensive. Moreover, only a few studies (e.g. LA-ICP-MS) $)^{8}$ deal with the issue of quantitative analysis of thin layers.

The use of LIBS could be advantageous since it is a relatively cheap technique that does not require high vacuum equipment or consumption of inert gases and it allows analysis of samples

${ }^{a}$ University of Pardubice, Institute of Environmental and Chemical Engineering, Studentska 573, 53210 Pardubice, Czech Republic. E-mail: tomas.cernohorsky@ upce.cz

${ }^{b}$ University of Pardubice, Faculty of Chemical Technology, Joint Laboratory of Solid State Chemistry of IMC and University of Pardubice, Studentska 573, 53210 Pardubice, Czech Republic

${ }^{c}$ Brno University of Technology, Faculty of Chemistry, Centre for Materials Research CZ.1.05/2.1.00/01.0012, Purkyňova 464/118, Brno, CZ-612 00, Czech Republic of different sizes without any pre-treatment. LIBS is a wellestablished tool for qualitative, semi-quantitative and quantitative analysis of surfaces. The principle of LIBS spectroscopy is the generation of micro-plasma above the surface of the sample with a laser pulse. The interaction of the laser beam with the sample leads to the melting and ablation of the material from the sample and subsequently to the formation of the plasma. The plasma under certain conditions has the same composition as the ablated material from the sample surface. The radiation emitted by excited atoms and ions in the plasma, which is characteristic for each element, is detected for a period of a few microseconds. Given the characteristics of the LIBS spectrometer or the excitation source (laser), respectively, it is possible to analyse even a very thin layer of the sample.

The LIBS technique was previously used for elemental mapping or profiling of solid samples mostly with the aim to achieve high depth resolution. ${ }^{9-12}$ Different research groups employed LIBS for characterization of chemical composition and element distributions on surfaces. ${ }^{\mathbf{1 3 , 1 4}}$ A quantitative and semi-quantitative LIBS analysis has been carried out also as a possible diagnostic tool for thin film elemental composition. ${ }^{15,16}$ A comparison of the IR nanosecond laser ablation parameters for polished and nanostructured titanium samples has been also performed in a recent study. ${ }^{17}$ The suitability of the LIBS technique for quantitative analysis of titanium in $\mathrm{Al}_{2} \mathrm{O}_{3}$ with a fixed plasma temperature calibration method was demonstrated in a recent study. ${ }^{18}$ However, none of these studies deals with the use of the LIBS technique for the determination of the surface density of an element.

The objective of the present study was to use a commercially available LIBS spectrometer for carrying out a fast and cheap quantitative analysis of a thin layer with titanium on a steel surface. The quantitative analysis has been carried out to determine the surface density of titanium in the ultrathin layer (nanometres) on a steel sheet. The effectiveness of LIBS has 
been evaluated by comparison of results obtained by other analytical techniques, namely XPS, WDXRF and LA-ICP-TOFMS.

\section{Experimental}

\subsection{LIBS instrumentation}

The commercially available fully compact LIBS instrument (LEA S500, Solar TII Ltd., Minsk, Belarus) was used in this work. The details of the instrument are given elsewhere. ${ }^{19}$ The system consists of a dual pulse Q-switched Nd:YAG laser operating at $1064 \mathrm{~nm}$ in a collinear dual-pulse arrangement. The laser emits two co-linear pulses of about 12 ns duration with variable energy per pulse, which can be set from 80 to $150 \mathrm{~mJ}$ at a maximum repetition rate of $20 \mathrm{~Hz}$. The interpulse delay can be set from 0 to $20 \mu \mathrm{s}$. The Czerny Turner spectrograph with a focal length of $500 \mathrm{~mm}$ and a grating of 1800 lines $\mathrm{mm}^{-1}$ provides a linear reciprocal dispersion of $1 \mathrm{~nm} \mathrm{~mm}^{-1}$. The spectrograph is fully sealed and can be purged by a low flow of argon or helium, consequently the wavelength range of the spectrograph can be set from 170 to $800 \mathrm{~nm}$. Recording of the spectra is carried out by means of a back thinned and front illuminated CCD-camera $(2048 \times 14$ pixels) with a fixed integration time (gate width) of 1 $\mathrm{ms}$. The optical spectral resolution is better than $0.03 \mathrm{~nm}$ for the whole spectral range. Spectra can be measured in $30 \mathrm{~nm}$ wide regions. The samples are placed inside the sample chamber on the top of the motorized positioning table and the samples can be automatically moved during the analysis. The sample chamber can be flushed with inert gas (He, Ar) or, alternatively, can be evacuated. Selection of the analyzed area of the sample surface is performed via an inbuilt video system with a magnification up to $100 \times$. The measurements are fully software controlled (position and number of points in the pattern).

\subsection{XPS instrumentation}

XPS analyses were carried out with an Axis Ultra DLD spectrometer using a monochromatic $\mathrm{Al} \mathrm{K} \alpha(h \nu=1486.7 \mathrm{eV}) \mathrm{X}$-ray source operating at $150 \mathrm{~W}(10 \mathrm{~mA}, 15 \mathrm{kV})$. The spectra were obtained using an analysis area of $\sim 300 \times 700 \mu \mathrm{m}$. The high resolution spectra, which are required for quantitative analysis, were measured with the step size $0.1 \mathrm{eV}$ and $20 \mathrm{eV}$ pass energy. Instrument base pressure was $2 \times 10^{-8} \mathrm{~Pa}$. Spectra were analyzed using CasaXPS software (version 2.3.15) and were charge corrected to the main line of the carbon $\mathrm{C}$ 1s spectral component $(\mathrm{C}-\mathrm{C}, \mathrm{C}-\mathrm{H})$ set to $284.80 \mathrm{eV}$. A standard Shirley background is used for all sample spectra.

\subsection{WDXRF instrumentation}

The determination of titanium in a thin layer was carried out using a bench-top vacuum wavelength dispersive X-ray fluorescence spectrometer Spectroscan Makc GVII (Spectron Optel, Wed Petersburg, Russia). The WDXRF spectrometer is equipped with a bent lithium fluoride (200) crystal in a Johansson arrangement. A Pd X-ray tube was operated at $40 \mathrm{kV}$ (current 2 $\mathrm{mA}$, output $80 \mathrm{~W}$ ). The apparatus is equipped with a sealed gas proportional detector filled with Xe.

\subsection{LA-ICP-TOF-MS instrumentation}

The Optimass 8000 ICP-oa-TOF-MS instrument (GBC Scientific Equipment Pty Ltd., Australia) was used throughout this study. The instrument, the detailed description of which is given elsewhere, ${ }^{20}$ was equipped with orthogonal acceleration (oa) and Time of Flight mass analyser. Instrument settings are summarised in Table 1.

\subsection{Sample characterization}

A Scanning Electron Microscope (SEM) JEOL JSM-5500LV at an acceleration voltage of the electron beam $15-20 \mathrm{kV}$ was adopted for visualization of typical representatives of ablation craters on the samples of the steel sheet. The depth of the craters was analyzed employing Digital holographic microscopy (DHM), for details see ref. 21 and 22 .

\subsection{Samples and reference values}

A set of sheet steel samples with an ultrathin titanium layer deposited on the layer of tin, which ensures better adhesion of titanium to the substrate (steel sheet), was used for the

Table 1 Instrumental operating conditions for LA-ICP-Oa-TOF-MS

ICP-oa-TOF-MS

Instrument

Acquisition time

Replicates

Sample intro time

Torch $X$ position

Torch $Y$ position

Torch $Z$ position

Gasbox nebulizer flow

Gasbox plasma flow

Gasbox auxiliary flow

Generator set power

Skimmer

Extraction

$\mathrm{Z} 1$

Y mean

Y deflection

$\mathrm{Z}$ lens mean

$\mathrm{Z}$ lens deflection

Lens body

Fill

Fill bias

Fill grid

Pushout grid

Pushout plate

Blanker

Reflectron

Multiplier gain

LA

Spot size

Laser energy

Laser shot frequency

Shutter delay

Scan rate

Helium gas flow
GBC Optimass 8000

5 [s]

1

1 [s]

$11.5[\mathrm{~mm}]$

$0.8[\mathrm{~mm}]$

$-0.4[\mathrm{~mm}]$

$0.91 \mathrm{~min}^{-1}$

$121 \mathrm{~min}^{-1}$

$0.81 \mathrm{~min}^{-1}$

1250 [W]

-1250 [V]

$-1250[\mathrm{~V}]$

$-450[\mathrm{~V}]$

$-450[\mathrm{~V}]$

$-4[\mathrm{~V}]$

$-1000[\mathrm{~V}]$

$-25[\mathrm{~V}]$

-150 [V]

$-37[\mathrm{~V}]$

0.1 [V]

$-2.0[\mathrm{~V}]$

$-470[\mathrm{~V}]$

567 [V]

$200[\mathrm{~V}]$

$600[\mathrm{~V}]$

2735 [V]

$200[\mu \mathrm{m}]$

5 [\%]

20 [Hz]

$10[\mathrm{~s}]$

$50\left[\mu \mathrm{m} \mathrm{s}^{-1}\right]$

$800\left[\mathrm{ml} \mathrm{min}^{-1}\right]$ 
experiments. The values of the surface density of titanium in the thin layer were determined by etching of a defined area on the sample surface and subsequent analysis of the obtained solution (ICP-OES, ICP-ToF-MS). The main disadvantage of this procedure is the necessity to etch a large area of steel to ensure the sufficient concentration for determination of titanium in solution. Unfortunately, this process is time consuming and inapplicable for the standard quality control process in the fabrication.

The values of surface densities obtained from etch analysis were validated using the reference XPS technique. The values obtained from etch and XPS analysis were in good agreement (correlation coefficient 0.994) and therefore were used for the calibration. However, given the cost and complexity of the device operation (analysis time 45 minutes per sample; high vacuum), this method is not suitable for the standard quality control process.

\subsection{Optimization of the experimental conditions}

In general, the optimization of LIBS analysis is a complex task. It is necessary to find the best combination of several basic parameters of the LIBS device (energy of laser pulses, delay between pulses, focal spot diameter, number of analytical points, spectrometer slit width, etc.) providing satisfactory values of basic characteristics of the obtained analytical method (LOD, dynamical range, etc.). The above-mentioned LIBS parameters are closely linked together and a minor change in one of them entails the necessity of a substantial change in the others. Development of the proper LIBS method is thus time consuming and large amounts of samples are consumed during this process. Our optimization procedure on the LIBS device was based on dividing LIBS parameters into the fixed and variable ones. Fixed parameters, which are typically the number of shots, the number of analytical points and the spectrometer slit width are set in the beginning of the optimization process with respect to the sample character and demands on the

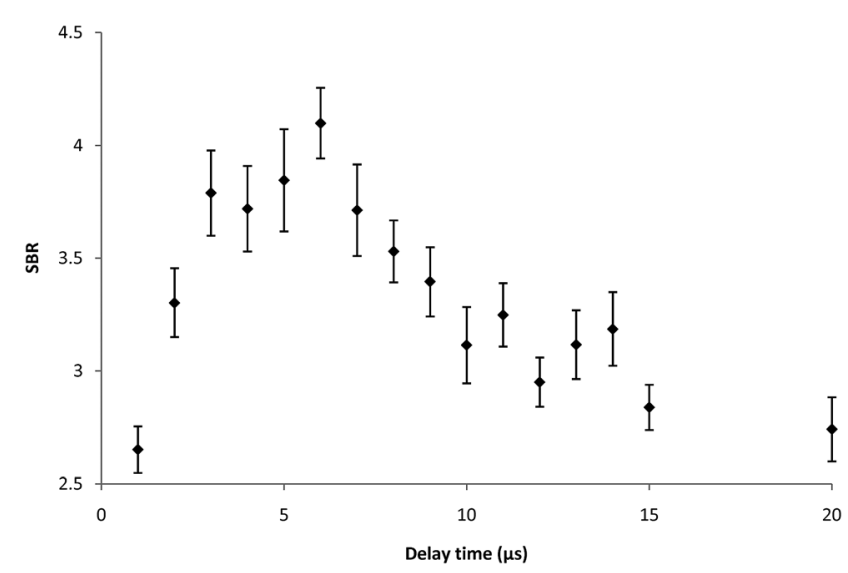

Fig. 1 Signal-to-background ratio (SBR) as a function of delay time. LIBS spectra of the sample with a Ti surface concentration of 0.6285 $\mathrm{mg} \mathrm{m}^{-2}$ recorded using the following LIBS conditions - laser energy $95 \mathrm{~mJ}$ (both pulses), spot diameter $800 \mu \mathrm{m}$, spectrometer slit width 15 $\mu \mathrm{m}$, and gate width $1 \mathrm{~ms}$. analytical process and they are not changed any more. These parameters were optimized previously. The most important variable parameters were energy of a laser pulse; interpulse delay and focal spot diameter. These parameters strongly influence the sensitivity, dynamic range and repeatability of the measurements. They were optimized simultaneously and proper parameters, signal-to-background ratio (SBR) and $\mathrm{RSD} \%$, were used for evaluation of measurement quality. The optimization of LIBS parameters was performed on the sample with the mean surface density of Ti being $0.6285 \mathrm{mg} \mathrm{m}^{-2}$. The Ti I $337.28 \mathrm{~nm}$ spectral line was repeatedly measured (three series - each with four shots), and then optimization criterion SBR values of the LIBS signal were evaluated (see Fig. 1-3). As can be seen from Fig. 1-3, LIBS analysis was most influenced by changing the parameters of laser pulse energy and focal spot diameter. The optimal parameters for the LIBS instrument used are listed in chapter 3.1.

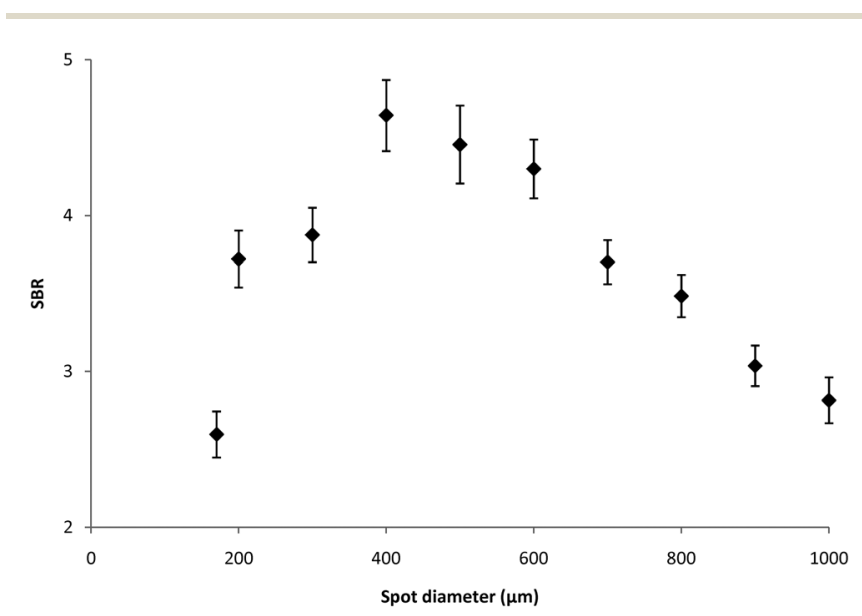

Fig. 2 Signal-to-background ratio (SBR) as a function of spot diameter. LIBS spectra of the sample with a Ti surface concentration of $0.6285 \mathrm{mg} \mathrm{m}^{-2}$ recorded using the following LIBS conditions - laser energy $105 \mathrm{~mJ}$ (both pulses), spectrometer slit width $15 \mu \mathrm{m}$, gate width $1 \mathrm{~ms}$ and acquisition delay of $6 \mu \mathrm{s}$.

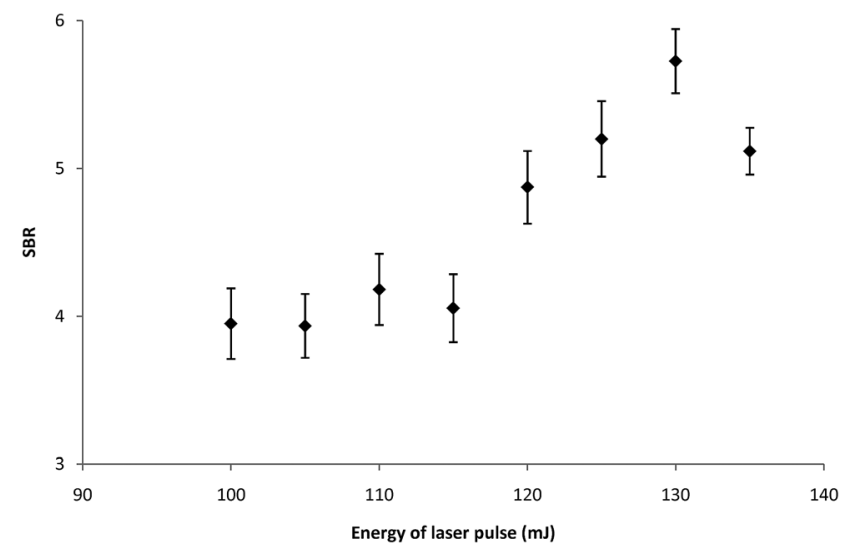

Fig. 3 Signal-to-background ratio (SBR) as a function of energy of laser pulse. LIBS spectra of the sample with a Ti surface concentration of $0.6285 \mathrm{mg} \mathrm{m}^{-2}$ recorded using the following LIBS conditions - spot diameter $400 \mu \mathrm{m}$, spectrometer slit width $15 \mu \mathrm{m}$, gate width $1 \mathrm{~ms}$ and acquisition delay of $6 \mu \mathrm{s}$. 


\section{Results and discussion}

\subsection{LIBS spectra and preferences}

In case of the samples analysed in this work a non-homogeneous layer of tin on the iron substrate was passivated by titanium. Titanium was present in the form of islands of $\mathrm{TiO}_{2}$ with diameters in the tens of nanometers. Simultaneously, the titanium surface density was very low (up to $1 \mathrm{mg} \mathrm{m}^{-2}$ ). Unfortunately, the most common techniques in quantitative analysis of the mentioned type of samples fail. The conventional etching technique requiring decomposition of the sample to form a solution, given the type of sample and the complexity of such an analysis, is unusable for the routine analysis. Due to the fact that the LIBS technique allows us to ablate the material from thin surface layer containing titanium, it can record the high signal intensity of spectral lines of titanium, despite its very low concentrations.

Based on the preliminary evaluation, the most suitable region of the titanium spectral lines was selected in the range from 320 to $350 \mathrm{~nm}$. The LIBS spectrum recorded in the $320-350 \mathrm{~nm}$ wavelength region contained almost all of the strong emission lines of Ti. These emission lines were sufficiently intense and relatively spectrally pure, without interferences from iron and tin lines. The typical LIBS spectrum of Ti obtained under LIBS analysis conditions is shown in Fig. 4 and 5.

Optimization of LIBS spectrometer parameters for determination of titanium was performed with respect to the properties of the sample. The aim of the optimization of the conditions was to achieve maximum values of the signal to background ratio (SBR) of Ti lines. The sample with the mean surface density of Ti $\left(0.6285 \mathrm{mg} \mathrm{m}^{-2}\right)$ was used for optimization of experimental conditions. The LIBS analysis was performed with a focal spot diameter of $400 \mu \mathrm{m}$, a laser pulse energy of $130 \mathrm{~mJ}, 1$ laser shots

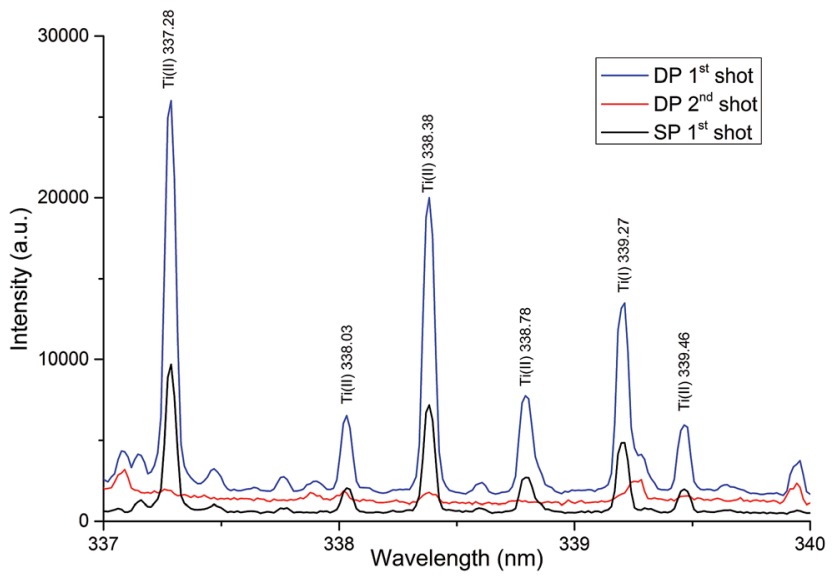

Fig. 5 LIBS spectra of the sheet sample with the surface concentration $1 \mathrm{mg} \mathrm{m}^{-2}$ recorded on a LIBS device under the optimal conditions laser energy $105 \mathrm{~mJ}$ (both pulses), spot diameter $400 \mu \mathrm{m}$, spectrometer slit width $15 \mu \mathrm{m}$, gate width $1 \mathrm{~ms}$ and acquisition delay of $6 \mu \mathrm{s}$.

per analytical point, 4 analytical points per sample and a spectrometer slit width of $15 \mu \mathrm{m}$. Typical delay time and gate width values of $6 \mu \mathrm{s}$ and $1 \mathrm{~ms}$, respectively, were used. All measurements were performed under the optimal operating conditions.

\subsection{The influence of ablation conditions on the spectra}

An important task in the development of a method for determination of $\mathrm{Ti}$ in the thin layer was the selection of an appropriate LIBS mode. As is evident from Fig. 4 and 5, a spectrally cleaner spectrum without interference lines from the substrate layer was recorded in the single-pulse mode. Simultaneously, in the singlepulse mode, it was also possible to detect much more lines of $\mathrm{Ti}$

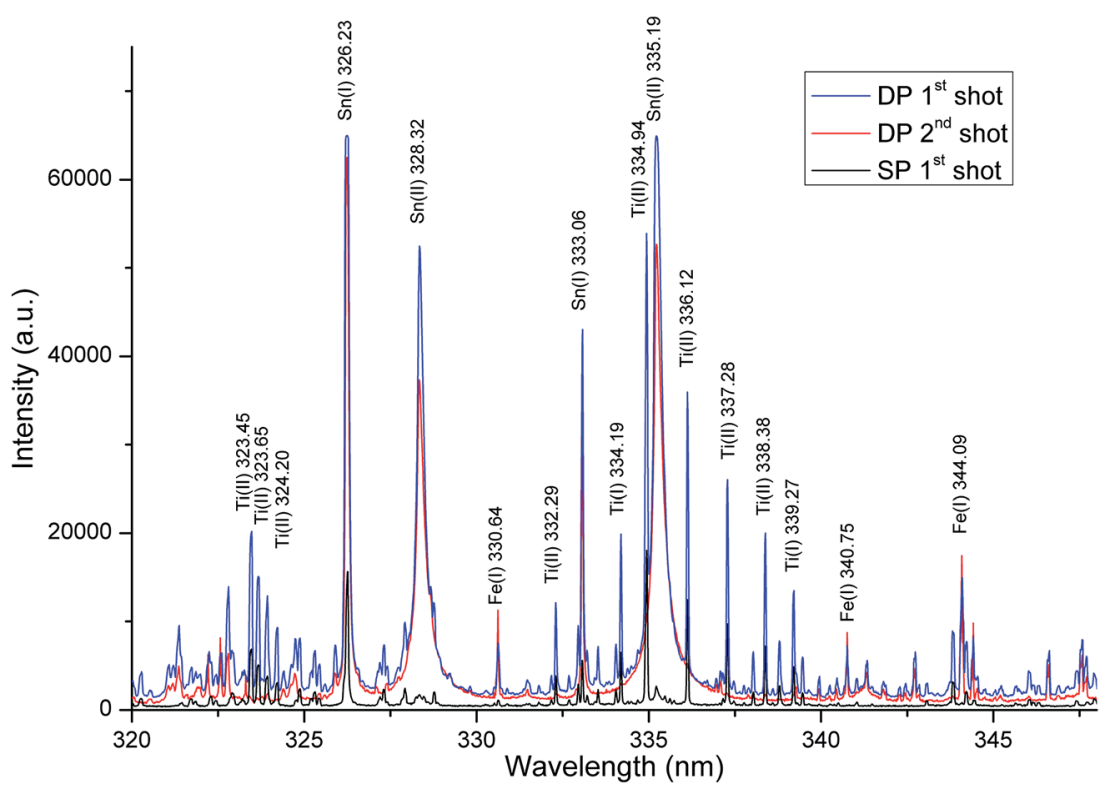

Fig. 4 LIBS spectrum (range of $30 \mathrm{~nm}$ ) obtained from the sheet sample with the surface concentration $1 \mathrm{mg} \mathrm{m}^{-2}$ recorded on a LIBS device under the optimal conditions - laser energy $105 \mathrm{~mJ}$ (both pulses), spot diameter $400 \mu \mathrm{m}$, spectrometer slit width $15 \mu \mathrm{m}$, gate width 1 ms and acquisition delay of $6 \mu \mathrm{s}$. 
and a higher ratio SBR of Ti lines was recorded. On the other hand, higher absolute intensities of Ti lines were obtained in a double-pulse mode. Nevertheless, the best fitted calibration curve was obtained in a double-pulse mode. According to Vrenegor, ${ }^{23}$ we assume that this fact is caused by more effective elimination of the matrix effect in the double-pulse mode in contrast to the single-pulse mode. Since double-pulse mode led to linear calibrations and at the same time to sufficient sensitivity and better RSD of the measurements, it was chosen as the optimal mode for the following measurements.

Under the optimal conditions, the depth of the crater after the first laser shot was about $150 \mathrm{~nm}$. The second laser shot created in the same place a crater with a depth of about $330 \mathrm{~nm}$ and the third laser shot created a crater with a depth of about $530 \mathrm{~nm}$. Fig. 6 shows the images of the individual craters and the result of DHM profilometry of the craters created by the laser shots focusing at the $400 \mu \mathrm{m}$.

Our assumption about ablation of the complete layer with titanium by the first laser shot (depth of crater $150 \mathrm{~nm}$ ) was verified by monitoring of the intensities of titanium lines. Under optimal conditions it was possible to fully ablate the layer with titanium just by the one laser shot. Subsequently, the second laser shot focused to the same spot provided the spectrum in which no lines of titanium were detected (see Fig. 4 and $5)$. In conjunction with the measurements of the crater depth it was possible to indirectly estimate that the titanium is present in the layer with the thickness less than $150 \mathrm{~nm}$. Simultaneously, the intensities of iron lines, which is the major component of the substrate of the layer containing titanium, were monitored. After the first laser shot, when the layer with
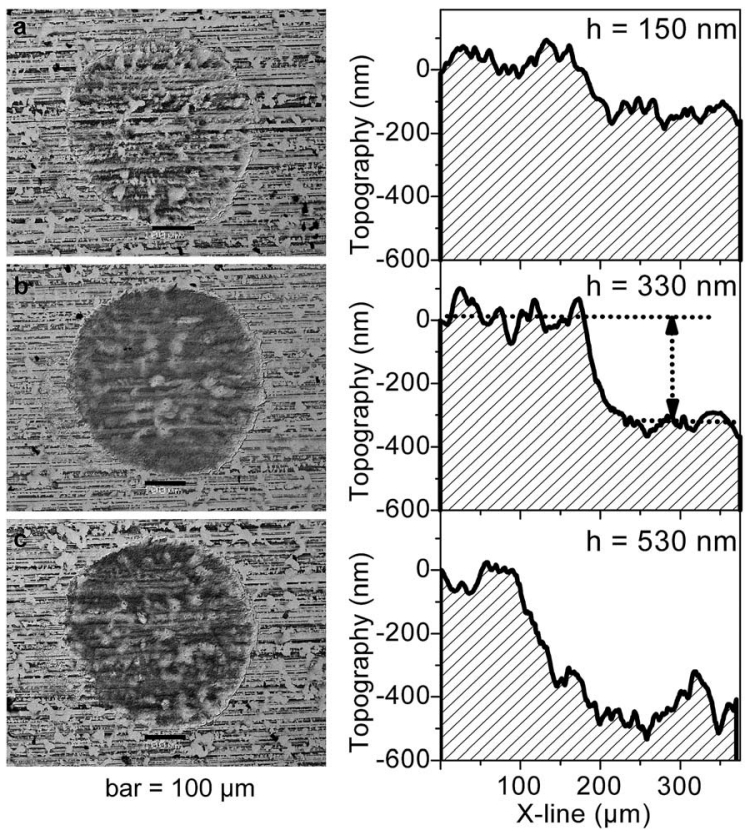

Fig. 6 Scanning Electron Microscopy-Backscattered Electron Imaging (SEM-BSE) visualization of the individual craters obtained by one (a), two (b), and three laser shots (c) on the sheet surface under the optimal conditions and the corresponding DHM topography of the craters. titanium was ablated predominantly, the intensities of titanium and tin lines were maximal. In contrast, during the second laser shot (in the same spot) only the substrate was ablated and intensities of iron lines increased sharply (without the presence of titanium lines).

Verification of the successful etching of the complete layer with titanium was carried out also using the LIBS analysis. As is evident from Fig. 7, the sample after etching provided a spectrum without the presence of titanium lines in contrast to the spectrum obtained from the same sample before etching. Due to a very low value of LIBS LOD it is a sufficient evidence of etching of the complete layer with the titanium. Furthermore, the spectrum obtained after the etching was the same (without the presence of titanium lines) as the spectrum obtained by the second double-pulse shot on the sample without the etching. The possibility of using LIBS for the control of the primary analysis (success of the complete etching) is another significant advantage of this technique.

\subsection{Calibration curves}

Under optimal conditions, the measurements to obtain a calibration curve using the LIBS device were performed. Several Ti lines in the region $320-340 \mathrm{~nm}$ were found to be considerably sensitive and provided a linear calibration. Specifically $\operatorname{Ti}(\mathrm{I})$ $337.28 \mathrm{~nm}$ line showed the best linear dependency on the surface density over a concentration range $0-1 \mathrm{mg} \mathrm{m}^{-2}$. Integral net intensities of the titanium analytical line with wavelength $337.28 \mathrm{~nm}$ were plotted against the corresponding titanium surface densities and the calibration model was suggested for the description of measured data (see Fig. 8 and Table 2). The calibration curves demonstrate that the LIBS signal intensity at $337.28 \mathrm{~nm}$ line increases linearly with the surface density of titanium. The generated calibration curve shows good linearity and precision. Each data point presented in Fig. 8 is the statistical average of 12 scans and the standard error (standard deviation divided by square root of 12) is depicted by the error bar.

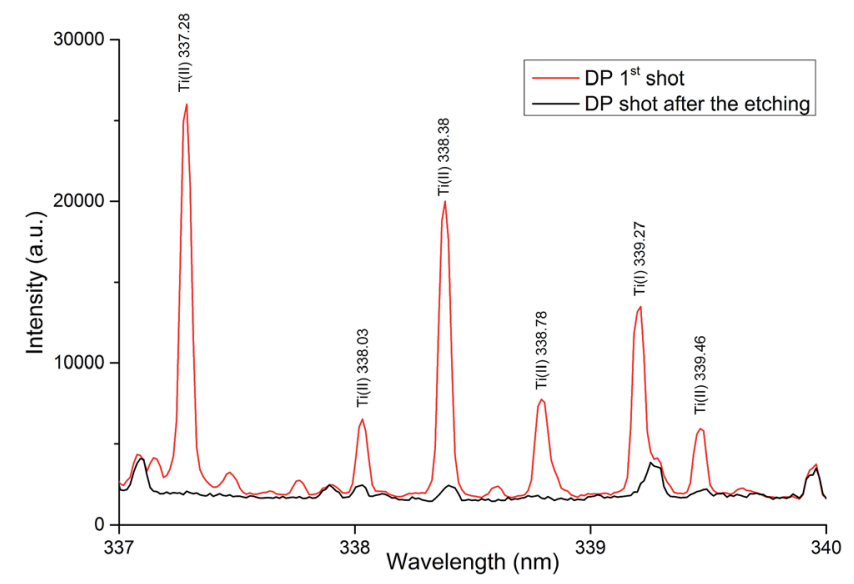

Fig. 7 LIBS spectra of the sheet sample with the surface concentration $1 \mathrm{mg} \mathrm{m}^{-2}$ recorded on a LIBS device after and before etching under the optimal conditions. 


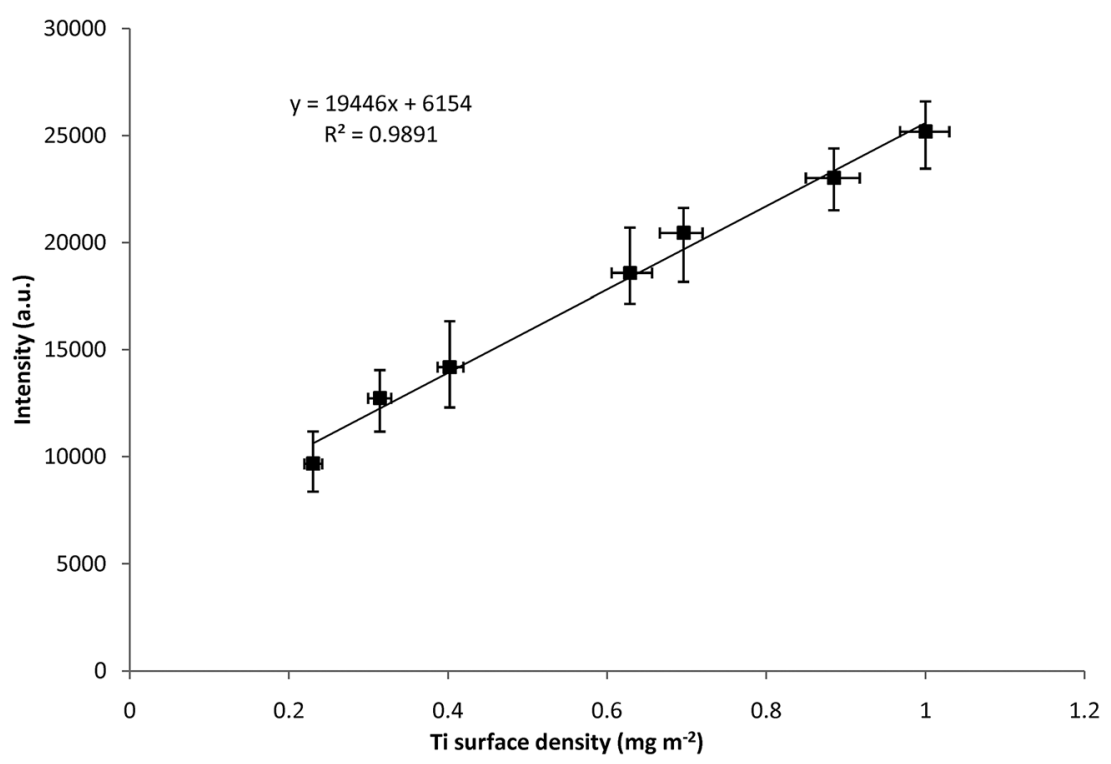

Fig. 8 Calibration curves for Ti I $337.28 \mathrm{~nm}$ concentration from the LIBS device in double-pulse mode. Error bars show standard deviation from multiple measurements at each value.

Table 2 Fitted parameters obtained from calibration curves: intercept of the curve (Intr), slope of the curve $\left(\beta_{1}\right)$, coefficient of determination $\left(R^{2}\right)$, Akaike information criterion $(\mathrm{AIC})$, and mean error of prediction (MEP)

\begin{tabular}{llllrl}
\hline Device & Intr & $\beta_{1}$ & $R^{2}$ & \multicolumn{1}{l}{ MEP } & AIC \\
\hline LIBS DP & 6154 & 19446 & 0.9891 & $6.9 \times 10^{5}$ & 92 \\
LIBS SP & 1787 & 6412 & 0.9726 & $7.6 \times 10^{5}$ & 94 \\
WDXRF & 5.297 & 228 & 0.9675 & $4.01 \times 10^{2}$ & 31 \\
LA-ICP-TOF-MS & 5375 & 1410 & 0.8678 & $7.8 \times 10^{5}$ & 107 \\
XPS & -1.23 & 23.96 & 0.9831 & $1.9 \times 10^{0}$ & 3.3 \\
\hline
\end{tabular}

The precision of any analytical instrument is defined as the repeatability of the measurement, and is usually estimated from the relative standard deviation. The RSD of the measurements on the LIBS device varied in the range of $4-11 \%$. The specific values of RSD are shown by the error bars, which represent the standard deviation from multiple measurements at each value (see Fig. 8).

A method of the determination surface density of Ti in the samples was also developed for the WDXRF spectrometer. The obtained calibration curves showed compliance with the calibration curves obtained using LIBS (see Table 2). However, the calibration curve was not accurate enough. The significantly worse fitting of the curve calculated for WDXRF compared to LIBS favours the LIBS technique for this type of analysis. Moreover, the sensitivity of the LIBS technique was much higher (100 times higher SBR) than that of the WDXRF technique. In the case of WDXRF the concentration of titanium in the samples was near to the detection limit of the instrument. The main advantage of the LIBS technique is, compared with the WDXRF, its speed, the possibility of local mapping elements onto the sample surface and no restrictions in terms of the geometry of the sample towards the excitation source. In addition, WDXRF analysis requires a relatively large area of the sample with sufficient flatness. The typical analysis time is $\mathbf{1 0}$ minutes per sample.

For the analysis of surface density of titanium in the samples the use of LA-ICP-TOF-MS was also tested. In the case of LA-ICPTOF-MS analysis it was possible to detect ${ }^{48} \mathrm{Ti}$ and ${ }^{49} \mathrm{Ti}$ isotopes with the values of SBR similar to the Ti lines from LIBS. On the other hand, the precision of analysis was slightly worse than WDXRF (see Table 2) and reproducibility was significantly unsatisfactory. The typical analysis time was similar to WDXRF (10 minutes per sample). A major disadvantage of the technique is the higher operating cost, namely consumption of helium and argon. Since the time needed and the cost of the analysis were higher than those in the case of LIBS, we did not continue with the investigation of LA-ICP-TOF-MS analysis.

The LOD of titanium was determined according to the definition $3 \sigma B / s$, where $\sigma B$ is the standard deviation of the blank (steel sheet without the protective layer containing titanium) and $s$ is the sensitivity determined by the slope of the calibration curve. We determined $\sigma B$ from 12 measurements of the blank signal under the same experimental conditions, where the sample was a steel sheet with the surface density of titanium $0 \mathrm{mg} \mathrm{m} \mathrm{m}^{-2}$. From the device point of view, LIBS provided the lowest LOD $0.008 \mathrm{mg} \mathrm{m}^{-2}$. The low value of LOD indicates that the LIBS technique is very sensitive for this type of analysis and the determination of the surface density is possible even for a much lower concentration than $0.2-1 \mathrm{mg} \mathrm{m}^{-2}$, which is a range desired by industry.

\section{Conclusion}

The results demonstrate the applicability of the LIBS technique for the determination of $\mathrm{Ti}$ in ultrathin layers at low concentrations. The proposed method of LIBS analysis eliminates the time-consuming decomposition of the sample and reduces the cost of analysis. Moreover, results from LIBS are consistent with 
Table 3 Overall comparison of used techniques

\begin{tabular}{llll}
\hline & LIBS & WDXRF & LA-ICP-TOF-MS \\
\hline Preparation of sample & None & Yes & None \\
Times of analysis & Second & Minutes & Minutes \\
Operating costs & None & Low & High \\
Reproducibility & Sufficient & Sufficient & Unsatisfactory \\
Sensitivity & High & Low & High
\end{tabular}

those obtained by the etching method. LIBS is a robust method, with a simple operation and without the use of vacuum or inert gas in the sample chamber. The total time of analysis including data capture and subsequent calculations was less than one minute without the sample preparation. The sensitivity of the LIBS technique is higher than that in the case of WDXRF, which provides a significantly worse fitted curve (results with more significant error). The advantage of the LIBS technique is the speed, the possibility of local mapping of elements and no restrictions in terms of the sample geometry towards the excitation source. The LIBS technique represents an interesting and promising application for elemental analysis of ultrathin layers in low concentrations. The results have shown that the compact commercial LIBS system is suitable for fast determination of titanium surface density and in this case even surpasses wellestablished and sophisticated techniques as WDXRF and LAICP-TOF-MS (see Table 3). The applicability verification in the laboratory conditions opens the possibility of implementing the LIBS technique in industry as an instrument for online measurements in production.

\section{References}

1 K. Cai, M. Muller, J. Bossert, A. Rechtenbach and K. D. Jandt, Appl. Surf. Sci., 2005, 250, 252-267.

2 Y. L. Jeyachandran, B. Karunagaran, S. K. Narayandass, D. Mangalaraj, T. E. Jenkins and P. J. Martin, Mater. Sci. Eng., A, 2006, 431, 277-284.

3 I. Shupyk, L. Lavisse, J.-M. Jouvard, M. C. Marco de Lucas, S. Bourgeois, F. Herbst, J.-Y. Piquemal, F. Bozon-Verduraz and M. Pilloz, Appl. Surf. Sci., 2009, 255, 5574-5578.

4 M. L. Franquelo, A. Duran, J. Castaing, D. Arquillo and J. L. Perez Rodriguez, Talanta, 2012, 89, 462-469.
5 M. B. Chamberlain and R. J. Lederich, Thin Solid Films, 1977, 41(2), 167-172.

6 M. Cwil, P. Konarski and J. Ciosek, Int. J. Mass Spectrom., 2007, 263(1), 54-58.

7 S. Meyer, R. Gorges and G. Kreisel, Thin Solid Films, 2004, 450, 276-281.

8 B. Hattendorf, J. Pisonero, D. Günther and N. Bordel, Anal. Chem., 2012, 84(20), 8771-8776.

9 K. Novotný, T. Vaculovič, M. Galiová, V. Otruba, V. Kanický, J. Kaiser, M. Liška, O. Samek, R. Malina and K. Páleníková, Appl. Surf. Sci., 2007, 253, 3834-3842.

10 H. Afkhami Ardakani and S. H. Tavassoli, Spectrochim. Acta, Part B, 2010, 65(3), 210-217.

11 P. Paris, et al., Fusion Eng. Des., 2011, 86, 1125-1128.

12 T. Canel, P. Demir, E. Kacar, B. Genc Oztoprak, E. Akman, M. Gunes and A. Demir, Opt. Laser Technol., 2013, 54, 257264.

13 W. Wessel, A. Brueckner-Foit, J. Mildner, L. Englert, L. Haag, A. Horn, M. Wollenhaupt and T. Baumert, Eng. Fract. Mech., 2010, 77, 1874-1883.

$14 \mathrm{H}$. Wiggenhauser, D. Schaurich and G. Wilsch, NDT\&E Int., 1998, 31(4), 307-313.

15 L. Caneve, F. Colao, F. Sarto, V. Spizzichino and M. Vadrucci, Spectrochim. Acta, Part B, 2005, 60, 1098-1102.

16 S. Almaviva, L. Caneve, F. Colao, R. Fantoni and G. Maddaluno, J. Nucl. Mater., 2012, 421, 73-79.

17 V. N. Lednev, S. M. Pershin, A. A. Ionin, S. I. Kudryashov, S. V. Makarov, A. E. Ligachev, A. A. Rudenko, R. A. Chmelnitsky and A. F. Bunkin, Spectrochim. Acta, Part $B, 2013,88,15-19$.

18 J. Zhang, G. Ma, H. Zhu, J. Xi and Z. Ji, J. Anal. At. Spectrom., 2012, 27, 1903-1908.

19 V. D. Kopachevskii and M. A. Krivosheeva, Refract. Ind. Ceram, 2007, 48(4), 255-258.

20 R. E. Sturgeon, J. W. H. Lam and A. Saint, J. Anal. At. Spectrom., 2000, 15, 607-616.

21 P. Knotek, D. Arsova, E. Vateva and L. Tichy, J. Optoelectron. Adv. Mater., 2009, 11, 391-394.

22 P. Knotek and L. Tichy, Mater. Res. Bull., 2012, 47, 42464251.

23 J. Vrenegor, R. Noll and V. Sturm, Spectrochim. Acta, Part B, 2005, 60, 1083-1091. 